NASA/TM—2008-214928

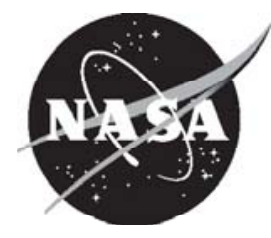

Stress Analysis and Fracture in Nanolaminate Composites

Christos C. Chamis

Glenn Research Center, Cleveland, Ohio 


\section{NASA STI Program . . . in Profile}

Since its founding, NASA has been dedicated to the advancement of aeronautics and space science. The NASA Scientific and Technical Information (STI) program plays a key part in helping NASA maintain this important role.

The NASA STI Program operates under the auspices of the Agency Chief Information Officer. It collects, organizes, provides for archiving, and disseminates NASA's STI. The NASA STI program provides access to the NASA Aeronautics and Space Database and its public interface, the NASA Technical Reports Server, thus providing one of the largest collections of aeronautical and space science STI in the world. Results are published in both non-NASA channels and by NASA in the NASA STI Report Series, which includes the following report types:

- TECHNICAL PUBLICATION. Reports of completed research or a major significant phase of research that present the results of NASA programs and include extensive data or theoretical analysis. Includes compilations of significant scientific and technical data and information deemed to be of continuing reference value. NASA counterpart of peer-reviewed formal professional papers but has less stringent limitations on manuscript length and extent of graphic presentations.

- TECHNICAL MEMORANDUM. Scientific and technical findings that are preliminary or of specialized interest, e.g., quick release reports, working papers, and bibliographies that contain minimal annotation. Does not contain extensive analysis.

- CONTRACTOR REPORT. Scientific and technical findings by NASA-sponsored contractors and grantees.

- CONFERENCE PUBLICATION. Collected papers from scientific and technical conferences, symposia, seminars, or other meetings sponsored or cosponsored by NASA.

- SPECIAL PUBLICATION. Scientific, technical, or historical information from NASA programs, projects, and missions, often concerned with subjects having substantial public interest.

- TECHNICAL TRANSLATION. Englishlanguage translations of foreign scientific and technical material pertinent to NASA's mission.

Specialized services also include creating custom thesauri, building customized databases, organizing and publishing research results.

For more information about the NASA STI program, see the following:

- Access the NASA STI program home page at http://www.sti.nasa.gov

- E-mail your question via the Internet to help@ sti.nasa.gov

- Fax your question to the NASA STI Help Desk at 301-621-0134

- Telephone the NASA STI Help Desk at 301-621-0390

- Write to: NASA Center for AeroSpace Information (CASI) 7115 Standard Drive Hanover, MD 21076-1320 
NASA/TM-2008-214928

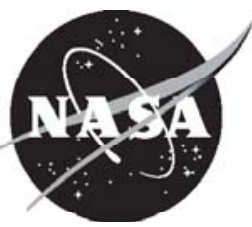

\section{Stress Analysis and Fracture in Nanolaminate Composites}

Christos C. Chamis

Glenn Research Center, Cleveland, Ohio

Prepared for the

SAMPE 2007

sponsored by the Society for the Advancement of Material and Process Engineering Baltimore, Maryland, June 3-7, 2007

National Aeronautics and

Space Administration

Glenn Research Center

Cleveland, Ohio 44135 
This work was sponsored by the Fundamental Aeronautics Program at the NASA Glenn Research Center.

Level of Review: This material has been technically reviewed by technical management.

Available from

NASA Center for Aerospace Information

7115 Standard Drive

Hanover, MD 21076-1320
National Technical Information Service 5285 Port Royal Road Springfield, VA 22161

Available electronically at http://gltrs.grc.nasa.gov 


\title{
Stress Analysis and Fracture in Nanolaminate Composites
}

\author{
Christos C. Chamis \\ National Aeronautics and Space Administration \\ Glenn Research Center \\ Cleveland, Ohio 44135
}

\begin{abstract}
Summary
A stress analysis is performed on a nanolaminate subjected to bending. A composite mechanics computer code that is based on constituent properties and nanoelement formulation is used to evaluate the nanolaminate stresses. The results indicate that the computer code is sufficient for the analysis. The results also show that when a stress concentration is present, the nanolaminate stresses exceed their corresponding matrix-dominated strengths and the nanofiber fracture strength.
\end{abstract}

\section{Introduction}

A nanocomposite (nanolaminate) is analyzed that is subjected to a bending moment (see fig. 1). This type of composite was chosen to be investigated because (1) the bottom and top plies can each be divided into subplies, from which the magnitudes of the stresses can be evaluated and (2) there is not a comparable analysis in the literature. The top and bottom plies are each assumed to be made from one type of nanofiber composite, and the core is made from 10 aligned nanocomposites of the same composition. A schematic of the nanocomposite section is shown in figure 2; the sliced subplies are shown in figure 3. Note that the two plies are each sliced into 10 slices to obtain a detailed stress distribution of the maximum bending stresses in the section. The stress analysis includes the stress distribution through the laminate thickness as well as the stresses in the two substructured plies. In addition, the corresponding strains are also computed for completeness. The objective of this paper is to describe the stresses in a nanoelement of a unidirectional nanolaminate subjected to a bending moment along the $\mathrm{x}$-direction.

\section{Nanocomposite Simulation Properties}

The nanofibers in this study are assumed to be Thornell T300 graphite fibers with a modulus of $6985 \mathrm{GPa}\left(1 \times 10^{9} \mathrm{psi}\right)$, a tensile strength of $800000 \mathrm{psi}(5.52 \mathrm{GPa})$, and a fiber diameter of $4.33 \times 10^{-6}$ in. $(110 \mathrm{~nm})$. The matrix is assumed to be an intermediate-modulus, high-tensile-strength polymer matrix. The properties for these two constituents are available and presented in tables I and II. The nanocomposite is usually made with relatively low fiber volume ratio (about 0.05 ) (ref. 1). Entering this value and the values in tables I and II in the composite mechanics computer code (ICAN/JAVA) (ref. 2), the following properties are predicted:

(1) The fiber volume ratio, void volume ratio, and matrix volume ratio, shown in figure 4

(2) The laminate configuration (ply thickness, fiber misalignment, and laminate thickness measured from the bottom ply), shown in figure 5

(3) The laminate thermal expansion coefficients, shown in figure 6

(4) The laminate fiber-dominated longitudinal modulus, shown in figure 7

(5) The matrix-dominated transverse moduli, shown in figure 8

(6) The corresponding shear moduli, shown in figure 9

(7) The corresponding Poisson's ratios, shown in figure 10 
The significance of the laminate properties shown in figures 7 to 10 are that (1) the horizontal spikes show that the two substructure plies represent the thickness averages. These two plies have 1/10 the average thickness and (2) they illustrate the discontinuity that exists between the core and the two end plies. Note that in figure 6, the matrix-dominated thermal expansion coefficients CTE22 and CTE33 at the spikes are about 4 times the fiber-dominated CTE11. This type of discontinuity is also apparent in figures 7 to 9. The discontinuity effects are somewhat different in figure 10. In this figure the fiberdominated Poisson's ratio NUL21 has the opposite effect than the Poisson's ratio NUL23, which is matrix dominated.

The laminate fiber-dominated tensile and compressive strengths (LSC11T and LSC11C, respectively) are shown in figure 11. This figure shows the same trend in the two end plies for LSC11T and LSC11C at the spikes that was described above for the thermal expansion coefficients. The spike effects are not as pronounced in figure 12, which shows the matrix-dominated strengths. It is worth commenting that the results described thus far are independent of loading.

The strains through the laminate thickness are shown in figure 13. In this figure, the two major assumptions for bending deformation through the thickness are clearly shown: (1) the line of bending strains due to the bending moment (orange) is linearly varying and (2) the line of Poisson strains (green) is also linearly varying, but having an opposite slope as it should have. However, the line of shear strains (blue) is " 0 " as it should be since there is in-plane shear loading.

The corresponding stresses are shown in figure 14. Note the two spikes indicating that this laminate behaves more like a sandwich where the core stresses are negligible (fig. 15) compared to the stresses in the two end plies where the stresses are of opposite sign. Note also that the transverse ply stress (SIG22) and the in-plane shear stress (SIG12) are near "0" as they should be since there are no loads in these two directions. The laminate combined stress failure criteria (modified distortion energy (ref. 3) and the Hill criterion (ref. 4)) are plotted in figure 16. The results in this plot show no fracture on the laminate scale.

These local stress concentration factors are shown in figure 17 around a small hole in the laminate (from ref. 5, see the appendix). The plot in figure 17 illustrates that the stress concentration factors reach a maximum at $90^{\circ}$ and $270^{\circ}$ from the load direction for $+\mathrm{Kxx}$ and $\mathrm{Kxy}$. The Kyy stress reaches maximum for $0^{\circ}, 180^{\circ}$, and back to $360^{\circ}$. Note that the maxima for Kxx and Kxy are equal in magnitude, with Kxy having a sharp discontinuity at $90^{\circ}$ and $270^{\circ}$; that is, Kxy jumps from a negative value to an equal positive value within a few degrees (about $4^{\circ}$ ). Even if the stresses in figures 14 and 15 are multiplied by 20 (the maximum stress concentration factor from fig. 17), the laminate stresses still do not cause any fracture based upon the corresponding strengths in figures 11 and 12.

\section{Stresses in a Nanoelement (Nanostresses) and Fracture}

The longitudinal and transverse flexural stresses from bending SF1L and SF1T in a nanofiber are plotted in figure 18. The range for these stresses is -200000 to 200000 psi ( -1.38 to $1.38 \mathrm{GPa}$ ). Upon multiplying these stresses with 20 (the stress concentration factor), the stresses becomes 4000000 psi (27.6 GPa), which is 5 times the fiber tensile strength of $800000 \mathrm{psi}(5.52 \mathrm{GPa})$ and 6.7 times the compressive strength $600000 \mathrm{psi}(4.14 \mathrm{GPa})$ in table I. Therefore, the nanofibers will start breaking all across the bottom and top nanoplies.

Figure 19 plots the corresponding longitudinal and transverse stresses in the matrix in a nanoelement. These stresses multiplied by the stress intensity factor will not cause any damage in the nanoscale matrix element. The plot for the nanoelement matrix-dominated stresses SM2BL and SM2BT shown in figure 20. As can be seen in this plot, when SM2BL is multiplied by the maximum stress concentration factor (20) from figure 17, it is about 800000 psi (5.52 GPa), and the matrix will definitely crack. Even without the multiplication of the stress concentration factor, the nanomatrix in the nanoelement of figure 20 will fracture. 
The normal and shear nanostresses are plotted in figure 21. As can be seen in this nanoelement, both the normal and the shearing stresses will fracture the matrix without the effects of stress concentration factors.

The important conclusions from the above discussion are that (1) the matrix will crack in nanoelements even without stress concentration effects and (2) the fibers will fracture in the nanoelement in the presence of stress concentration.

\section{Concluding Remarks}

The concluding remarks from an investigation on the stresses in a unidirectional nanolaminate (composite) are the following:

1. The composite mechanics incorporated in a composite mechanics computer code based on constituent materials and a nanoscale element is sufficient for stress analysis of a nanocomposite laminate in bending.

2. The matrix-dominated stresses will fracture the matrix in the nanoelement even without stress concentration or residual stresses.

3. The fibers in a nanoelement will fracture when the stress concentration is accounted for.

4. Nanolaminate geometric and material properties are not affected by loading conditions in linear mechanics nanolaminate theory described herein.

5. The bending stresses in a nanolaminate behave the same as a sandwich where the top and bottom nanoplies exhibit a substantial increase in stress from the core material.

6. It is important to evaluate the stresses in a nanoelement even when the nanolaminate composites do not show any stresses reaching their limits based upon their corresponding strengths.

\section{References}

1. Chamis, Christos C.; Handler, Louis M.; and Manderscheid, Jane M.: Composite Nanomechanics: A Mechanistic Properties Prediction. NASA TM-2007-214673, 2007.

2. Handler, Louis M.; and Chamis, Christos C.: Integrated Composite Analyzer (ICAN/JAVA). http://www.grc.nasa.gov/WWW/StructMech/ICAN/indes.html Accessed Aug. 7, 2007.

3. Chamis, C.C.: Failure Criteria for Filamentary Composites. NASA TN-D-5367, 1969.

4. Hoffman, Oscar: The Brittle Strength of Orthotropic Materials. J. Compos. Mater., vol. 1, 1967, pp. 200-206.

5. Lekhnitskii, S.C.: Anisotropic Plates. Gordon and Breach, New York, NY, 1968. Translation. (Previously cited in Anizotropnye Plastinki.) 


\section{Appendix \\ Stress Concentration Around a Small Hole in Composite Plates}

The stress concentration around a small hole in composite plates (see fig. 22) is evaluated by the equations from reference 5 :

$$
\begin{gathered}
\frac{\sigma_{c \theta \theta}}{\sigma_{c x x}}=\frac{E_{c \theta \theta}}{E_{c x x}}\left\{R_{o}\left[\left(R_{O}+R_{D I}\right) \sin ^{2} \varphi-\cos ^{2} \varphi\right] \cos ^{2} \theta+\left[\left(1+R_{D I}\right) \cos ^{2} \varphi-R_{O} \sin ^{2} \varphi\right] \sin ^{2} \theta\right. \\
\left.-\frac{R_{D I}}{4}\left(1+R_{O}+R_{D I}\right) \sin 2 \varphi \sin 2 \theta\right\} \\
R_{o}=\sqrt{E_{c x x} / E_{c y y}} \\
R_{D I}=\left[2\left(\frac{E_{c x x}}{E_{c y y}}-v_{c x y}\right)+\frac{E_{c x x}}{G_{c x y}}\right]^{1 / 2} \\
\frac{\sigma_{c \theta \theta}}{\sigma_{c x y}}=\frac{E_{o \theta \theta}}{2 E_{c x x}}\left(1+R_{o}+R_{D I}\right)\left\{-R_{D I} \cos 2 \varphi \sin 2 \theta+\left[\left(1+R_{o}\right) \cos 2 \theta R_{o}-1\right] \sin 2 \varphi\right\}
\end{gathered}
$$

where

$\sigma_{c x x}$ is the composite stress along the $\mathrm{x}$-axis

$\sigma_{c \theta \theta}$ is the composite stress along the $\theta$-axis

$E_{c x x}$ is the modulus along the composite x-axis

$E_{c \theta \theta}$ is the modulus along the angle $\theta$, which varies from $0^{\circ}$ to $360^{\circ}$

$R_{o}$ is defined by equation (2)

$R_{D 1}$ is defined by equation (3)

$\theta$ is the angle at which the stress concentration is evaluated

$\varphi$ is the angle that the principal plate axes are located with respect to the loading $x$-axis

$v_{c x y}$ is Poisson's ratio when stress is applied in the $\mathrm{x}$-direction

$G_{c x y}$ is the shear modulus in the x,y-plane

Note there are no strengths in the above equations, only stiffnesses. 
TABLE I.-T300 GRAPHITE FIBER PROPERTIES

\begin{tabular}{|c|c|c|c|}
\hline Property $^{\mathrm{a}}$ & Symbol $^{\mathrm{b}}$ & Value & Units $^{c}$ \\
\hline Number of fibers per end & $\mathrm{Nf}$ & 1.0 & Number \\
\hline Filament equivalent diameter & $\mathrm{df}$ & $2.756 \times 10^{-6}$ & in. \\
\hline Weight density & Rhof & .064 & $\mathrm{lb} / \mathrm{in}^{3}$ \\
\hline Normal modulus (11) & Ef11 & $1.0 \times 10^{9}$ & psi \\
\hline Normal modulus (22) & Ef22 & $7.0 \times 10^{7}$ & psi \\
\hline Poisson’s ratio (12) & Nuf12 & 0.20 & Nondimensional \\
\hline Poisson’s ratio (23) & Nuf23 & .25 & Nondimensional \\
\hline Shear modulus (12) & Gf12 & $5.0 \times 10^{7}$ & psi \\
\hline Shear modulus (23) & Gf23 & $3.5 \times 10^{7}$ & psi \\
\hline Thermal expansion coefficient (11) & A1faf11 & $-5.5 \times 10^{-7}$ & in./in. $/{ }^{\circ} \mathrm{F}$ \\
\hline Thermal expansion coefficient (22) & Alfaf22 & $5.6 \times 10^{-6}$ & in. $/ \mathrm{in} . /{ }^{\circ} \mathrm{F}$ \\
\hline Heat conductivity (11) & Kf11 & 444.0 & $\mathrm{Btu} / \mathrm{hr} / \mathrm{ft}^{2} /{ }^{\circ} \mathrm{F} / \mathrm{in}$. \\
\hline Heat conductivity (22) & Kf22 & 4.0 & $\mathrm{Btu} / \mathrm{hr} / \mathrm{ft}^{2} /{ }^{\circ} \mathrm{F} / \mathrm{in}$. \\
\hline Heat capacity & Cf & 0.22 & $\mathrm{Btu} / \mathrm{lb} /{ }^{\circ} \mathrm{F}$ \\
\hline Dielectric strength (11) & KeF11 & 0.0 & V/in. \\
\hline Dielectric strength (22) & Kef22 & 0.0 & V/in. \\
\hline Dielectric constant (11) & Gamma11 & 0.0 & in./V \\
\hline Dielectric constant (22) & Gamma22 & 0.0 & in./V \\
\hline Capacitance & Cef & 0.0 & $\mathrm{~V}$ \\
\hline Resistivity & Ref & 0.0 & $\Omega$-in. \\
\hline Tensile strength & SfT & $8.0 \times 10^{5}$ & psi \\
\hline Compressive strength & SfC & $6.0 \times 10^{5}$ & psi \\
\hline Shear strength & SfS & $4.0 \times 10^{5}$ & psi \\
\hline Normal damping capacity (11) & psi11f & 0.38 & \% energy \\
\hline Normal damping capacity (22) & psi22f & 6.3 & \% energy \\
\hline Shear damping capacity (12) & psi12f & 3.34 & \% energy \\
\hline Shear damping capacity (23) & psi23f & 6.3 & \% energy \\
\hline Melting temperature & TMf & 6000.0 & ${ }^{\circ} \mathrm{F}$ \\
\hline
\end{tabular}

${ }^{\mathrm{a}}$ Numbers in parenthesis correspond to axis directions defined in figure 1(b).

bSymbols used in computer code ICAN/JAVA.

${ }^{\mathrm{c}}$ Conversions: $1 \mathrm{in} .=2.54 \mathrm{~cm}, 1 \mathrm{psi}=6.9 \mathrm{~Pa}, 1 \mathrm{in} . / \mathrm{in} . /{ }^{\circ} \mathrm{F}=9 / 5 \mathrm{~cm} / \mathrm{cm} /{ }^{\circ} \mathrm{C}, 1 \mathrm{btu}=1055 \mathrm{~J}$, $1 \mathrm{lb}=4.448 \mathrm{~N}$. 
TABLE II.-POLYMER MATRIX PROPERTIES

\begin{tabular}{|c|c|c|c|}
\hline Property & Symbol $^{\mathrm{a}}$ & Value & Units $^{\mathrm{b}}$ \\
\hline Weight density & Rhom & 0.044 & lb/in. ${ }^{3}$ \\
\hline Normal modulus & Em & 500000.0 & psi \\
\hline Poisson’s ratio & Num & .35 & Nondimensional \\
\hline Thermal expansion coefficient & Alfa m & $3.6 \times 10^{-5}$ & in. $/$ in. $/{ }^{\circ} \mathrm{F}$ \\
\hline Heat conductivity & $\mathrm{Km}$ & 0.008681 & $\mathrm{Btu} / \mathrm{hr} / \mathrm{ft}^{2} /{ }^{\circ} \mathrm{F} / \mathrm{in}$. \\
\hline Heat capacity & $\mathrm{cm}$ & .25 & $\mathrm{Btu} / \mathrm{lb} /{ }^{\circ} \mathrm{F}$ \\
\hline Dielectric strength & Kem & 0.0 & V/in. \\
\hline Dielectric constant & Gammam & 0.0 & in. $/ \mathrm{V}$ \\
\hline Capacitance & Cem & 0.0 & $\mathrm{~V}$ \\
\hline Resistivity & Rem & 0.0 & $\Omega$-in. \\
\hline Moisture expansion coefficient & Betam & .0033 & in./in./\% moisture \\
\hline Diffusivity & $\mathrm{Dm}$ & $2.16 \times 10^{-7}$ & in. ${ }^{2} / \mathrm{hr}$ \\
\hline Saturation & $\mathrm{Mm}$ & 0.0 & \% moisture \\
\hline Tensile strength & SmT & 15000.0 & psi \\
\hline Compressive strength & $\mathrm{SmC}$ & 35000.0 & psi \\
\hline Shear strength & $\mathrm{SmS}$ & 13000.0 & psi \\
\hline Allowable tensile strain & eps $\mathrm{mT}$ & 0.02 & in./in. \\
\hline Allowable compression strain & eps $\mathrm{mC}$ & .05 & in./in. \\
\hline Allowable shear strain & eps mS & .035 & in./in. \\
\hline Allowable torsional strain & eps mTOR & .035 & in./in. \\
\hline Normal damping capacity & psiNM & 6.6 & \% energy \\
\hline Shear damping capacity & psiSm & 6.9 & \% energy \\
\hline Void heat conductivity & $\mathrm{Kv}$ & .0012 & $\mathrm{Btu} / \mathrm{hr} / \mathrm{in} . /{ }^{\circ} \mathrm{F}$ \\
\hline Glass transition temperature & Tgdr & 420.0 & ${ }^{\circ} \mathrm{F}$ \\
\hline Melting temperature & $\mathrm{TMm}$ & 0.0 & ${ }^{\circ} \mathrm{F}$ \\
\hline
\end{tabular}

${ }^{\mathrm{a}}$ Symbols used in computer code ICAN/JAVA.

${ }^{\mathrm{a} C o n v e r s i o n s: ~} 1 \mathrm{in} .=2.54 \mathrm{~cm}, 1 \mathrm{psi}=6.9 \mathrm{~Pa}, 1 \mathrm{in} . / \mathrm{in} . /{ }^{\circ} \mathrm{F}=9 / 5 \mathrm{~cm} / \mathrm{cm} /{ }^{\circ} \mathrm{C}, 1 \mathrm{btu}=1055 \mathrm{~J}$, $1 \mathrm{lb}=4.448 \mathrm{~N}$. 


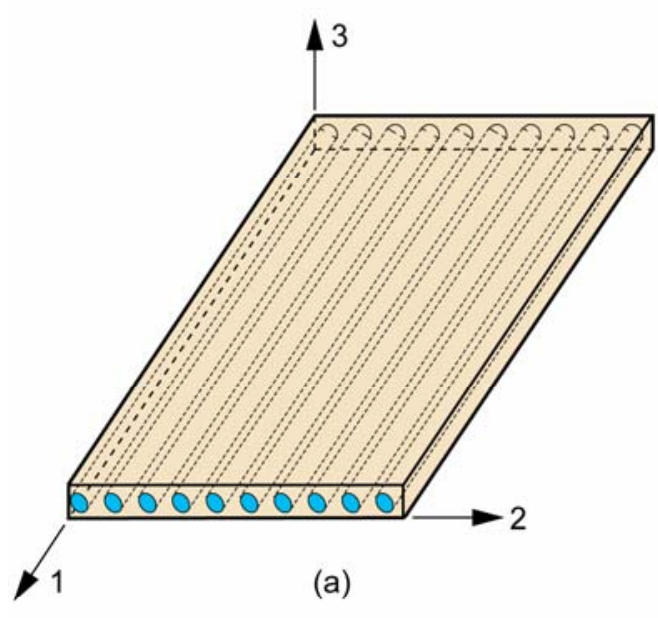

(a)
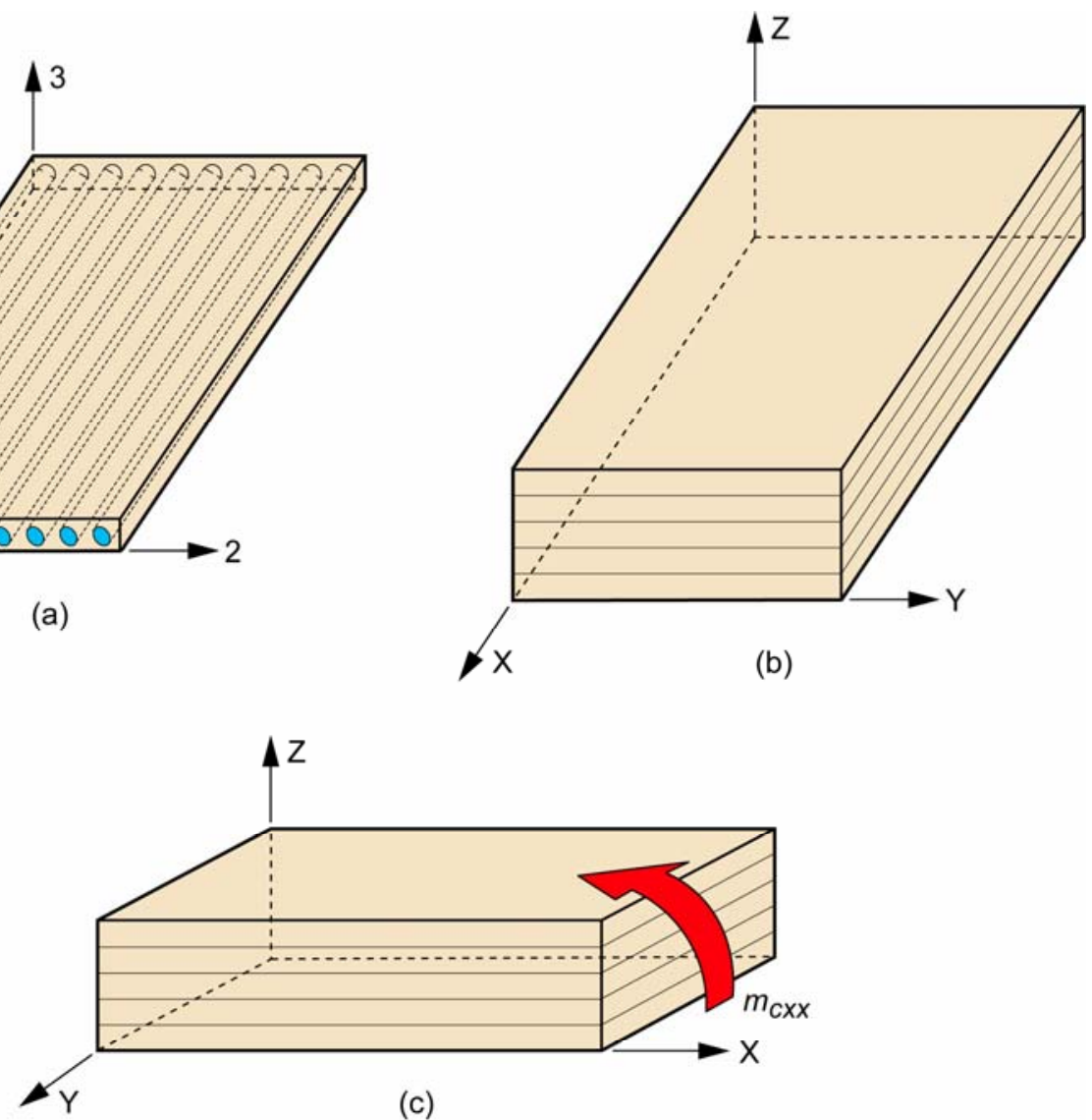

(c)

Figure 1.-Definitions of nanocomposite axes. (a) Nanoply material axes $(1,2,3)$. (b) Nanolaminate structural axes $(X, Y, Z)$. (c) Loaded structural configuration where $m_{c x x}$ represents the bending moment. 


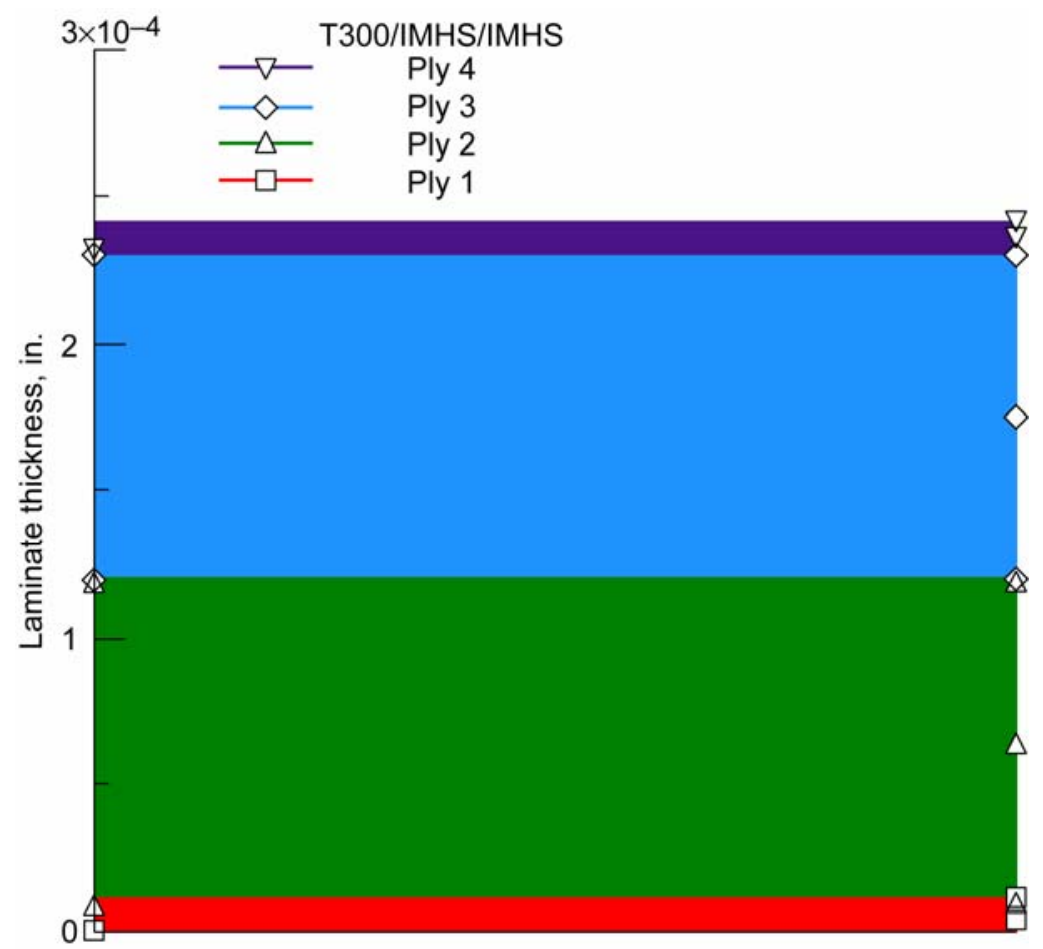

Figure 2.-Through-thickness schematic of T300 graphite fiber, intermediate modulus high-strength (IMHS) polymer matrix nanolaminate $(1$ in. $=2.54 \mathrm{~cm})$.

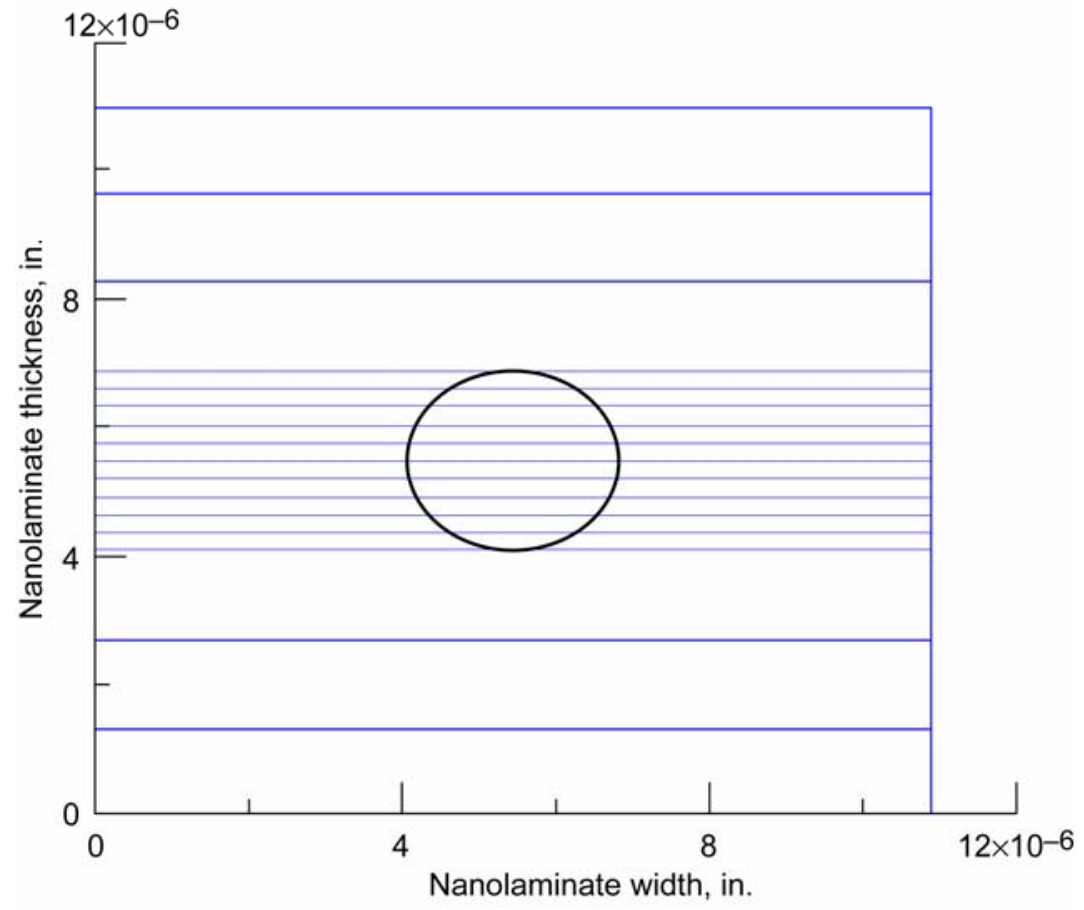

Figure 3.-Substructure of nanofiber ply $(1 \mathrm{in} .=2.54 \mathrm{~cm})$. 


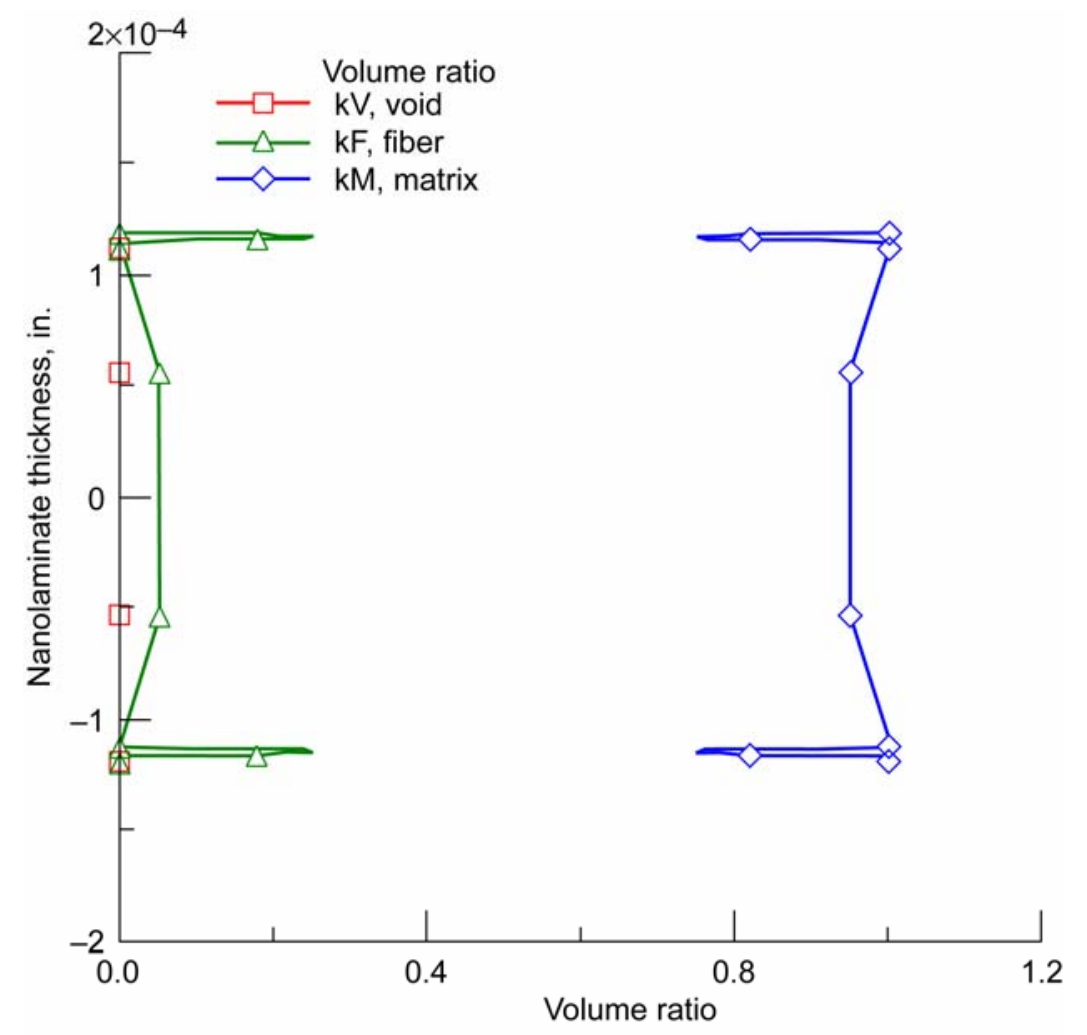

Figure 4.-Nanolaminate fabrication variables.

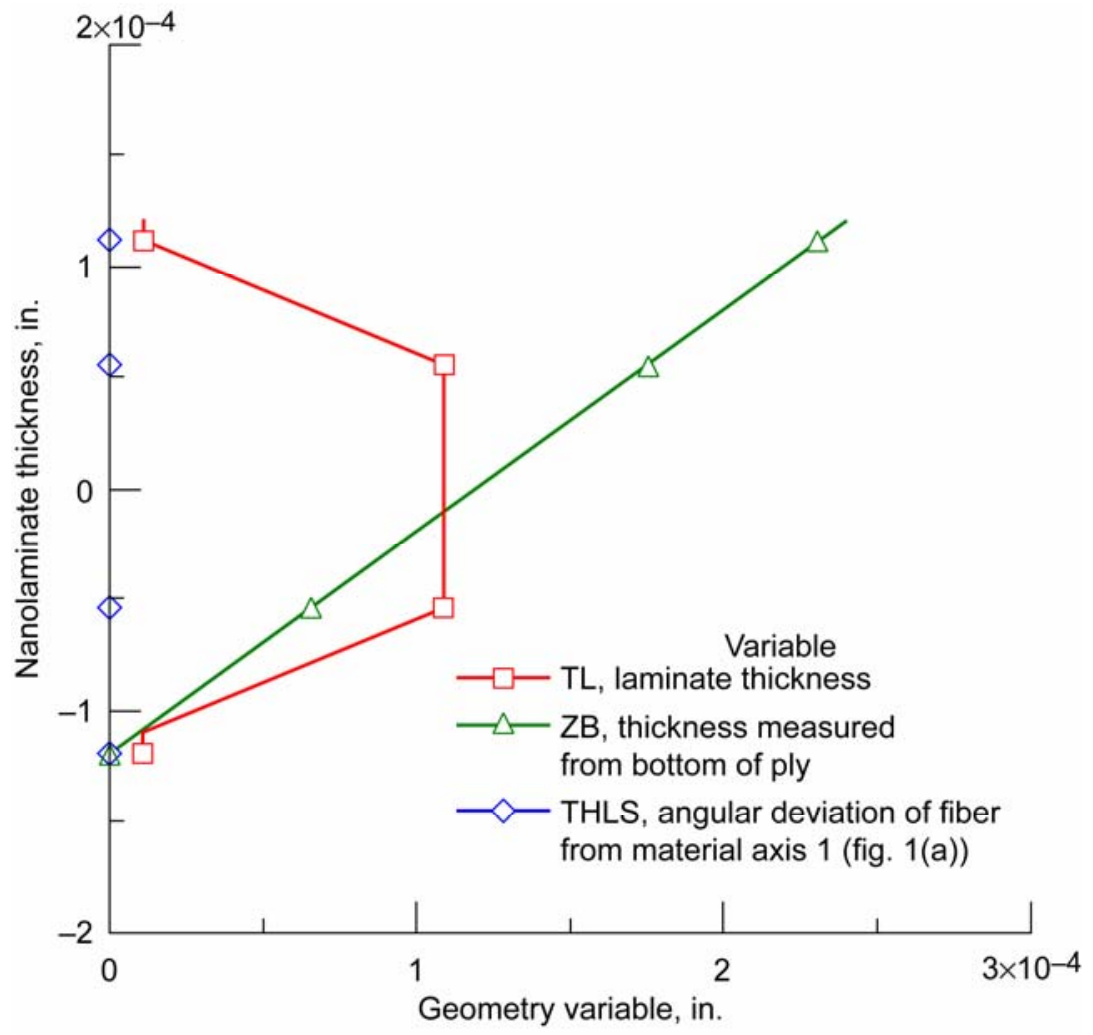

Figure 5. -Nanofiber ply geometry $(1 \mathrm{in} .=2.54 \mathrm{~cm})$. 


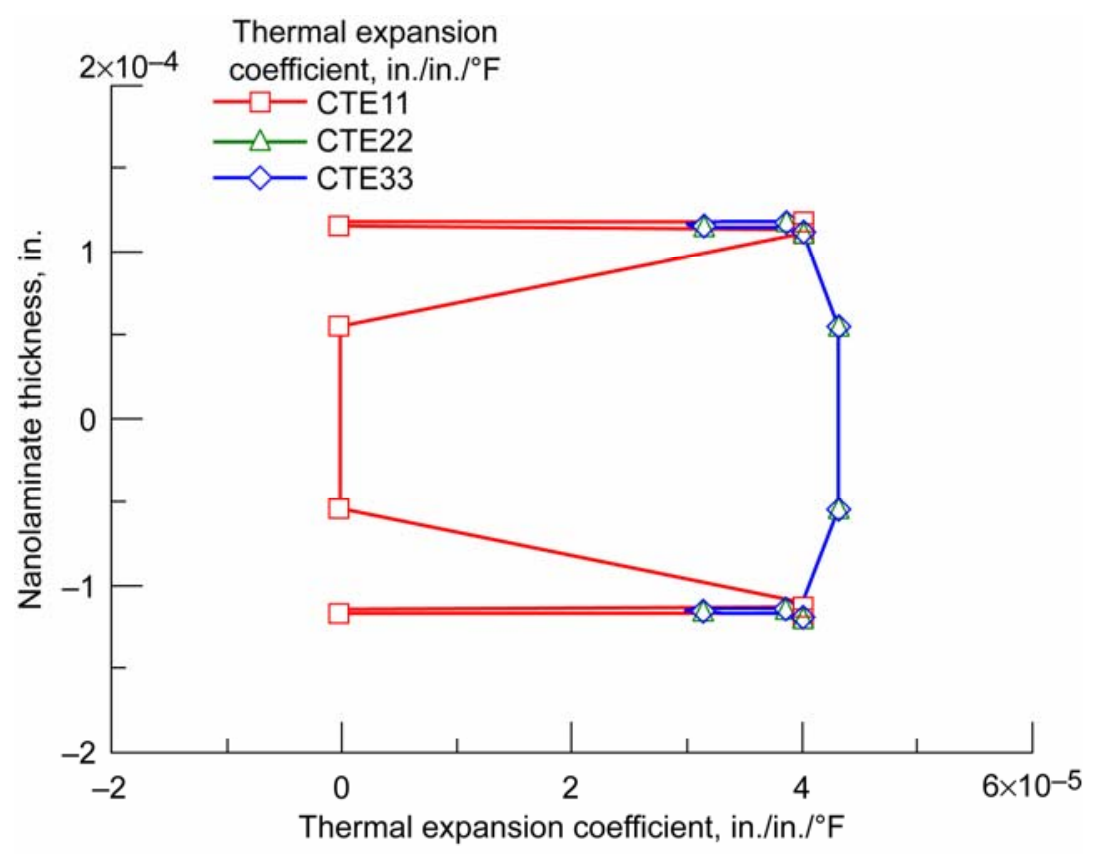

Figure 6.-Nanolaminate thermal expansion coefficients, CTE. Numbers on symbols refer to material axes shown in figure 1(a) ( 1 in. $/$ in. $/{ }^{\circ} \mathrm{F}=9 / 5 \mathrm{~cm} / \mathrm{cm} /{ }^{\circ} \mathrm{C}, 1$ in. $\left.=2.54 \mathrm{~cm}\right)$.

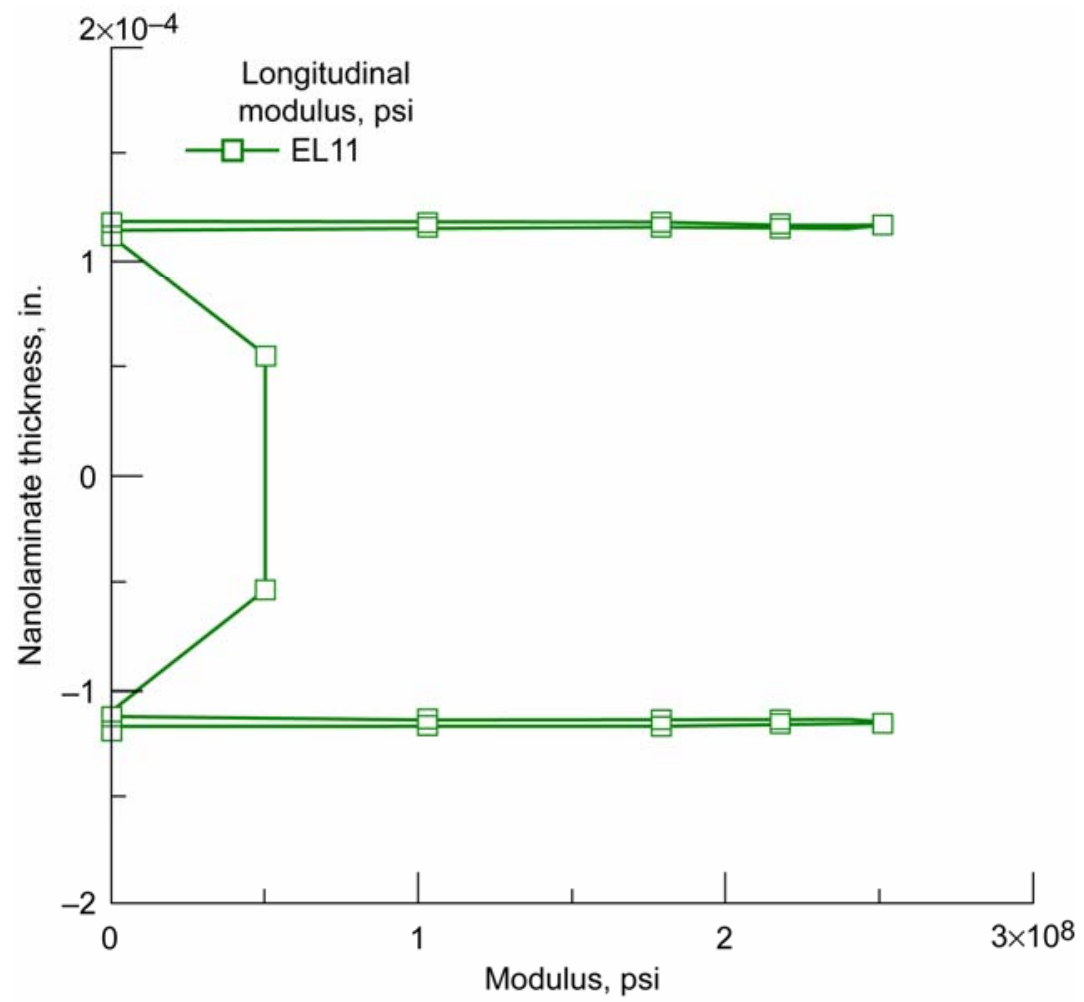

Figure 7.-Nanolaminate longitudinal modulus. Numbers on symbol refer to material axes shown in figure $1(\mathrm{a})(1 \mathrm{psi}=6.9 \mathrm{~Pa}, 1 \mathrm{in} .=2.54 \mathrm{~cm})$. 


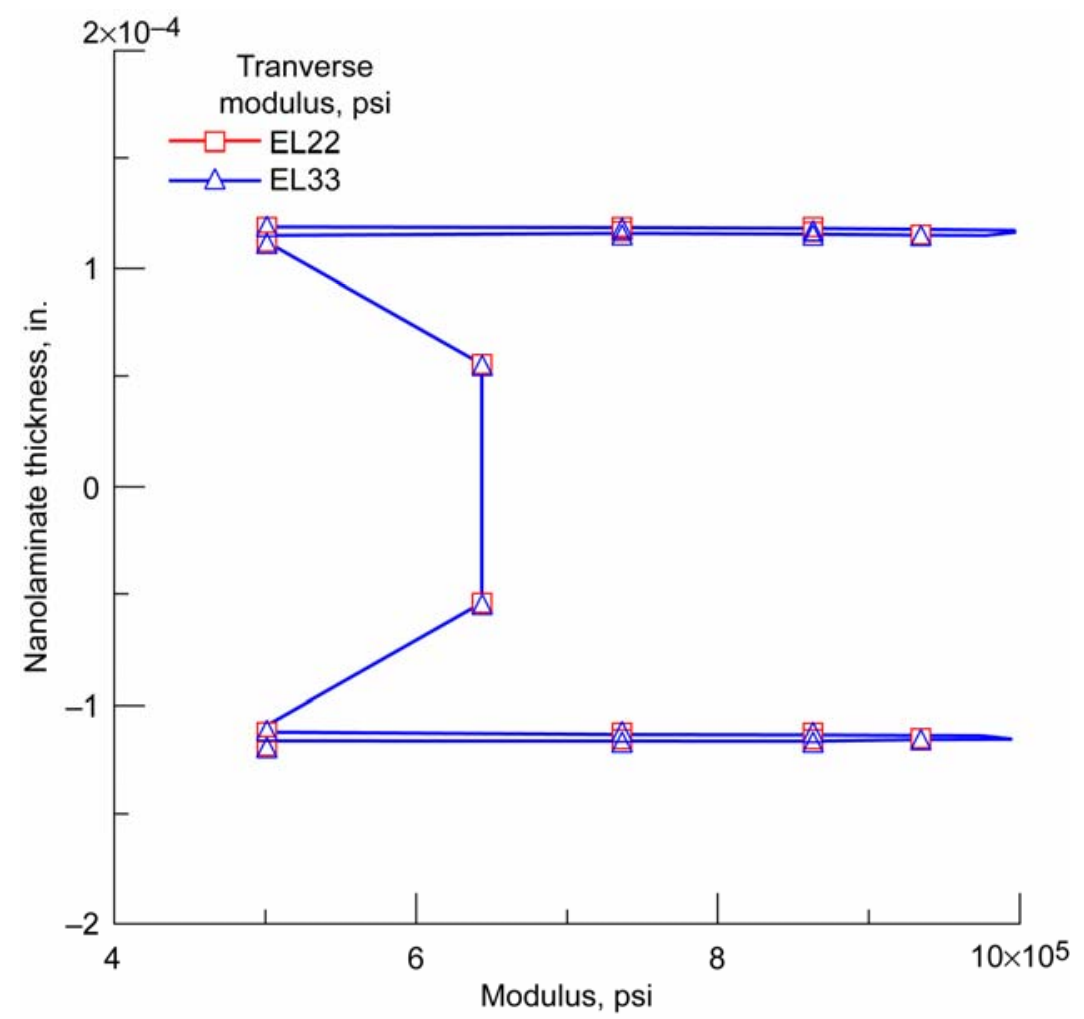

Figure 8.-Nanolaminate transverse moduli. Numbers on symbols refer to material axes shown in figure $1(\mathrm{a})(1 \mathrm{psi}=6.9 \mathrm{~Pa}, 1 \mathrm{in} .=2.54 \mathrm{~cm})$.

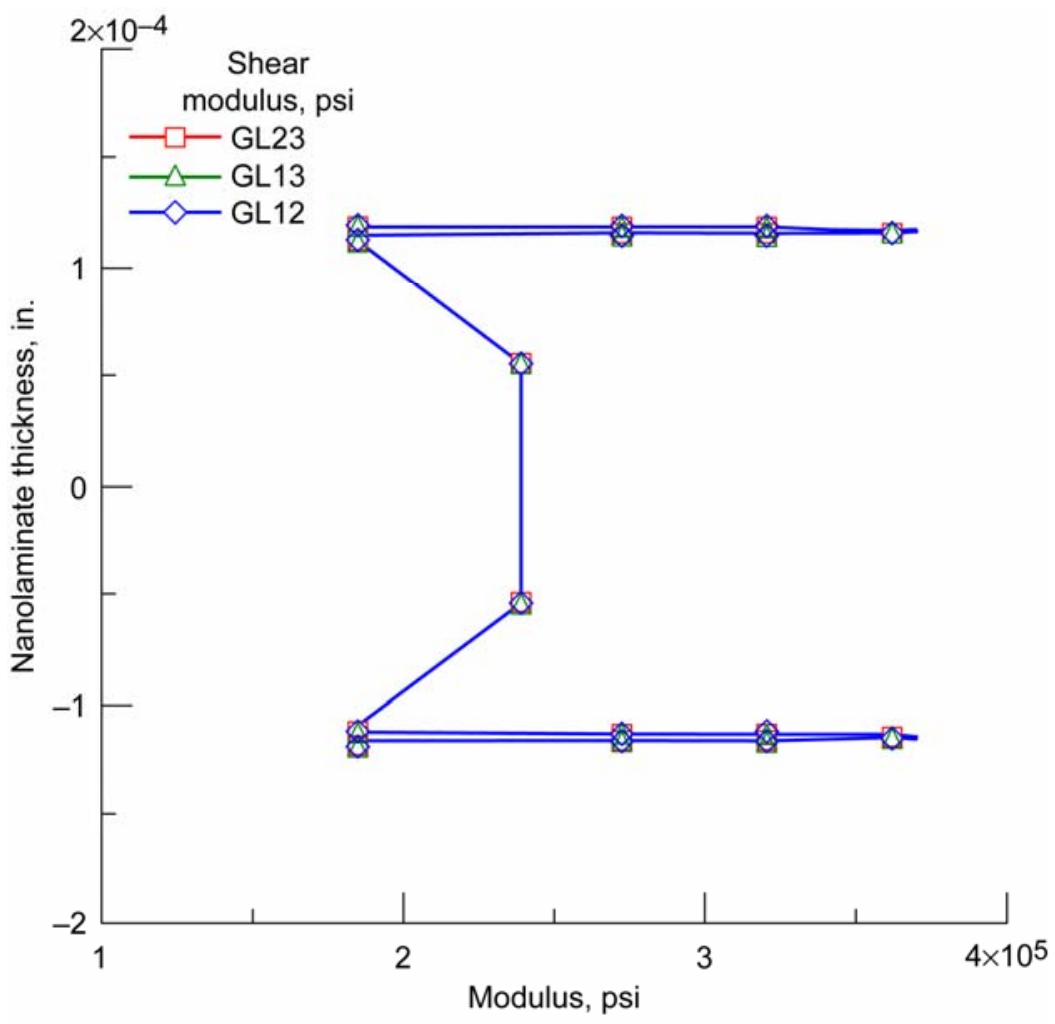

Figure 9.-Nanolaminate shear moduli. Numbers on symbols refer to material axes shown in figure $1(\mathrm{a})(1 \mathrm{psi}=6.9 \mathrm{~Pa}, 1 \mathrm{in} .=2.54 \mathrm{~cm})$. 


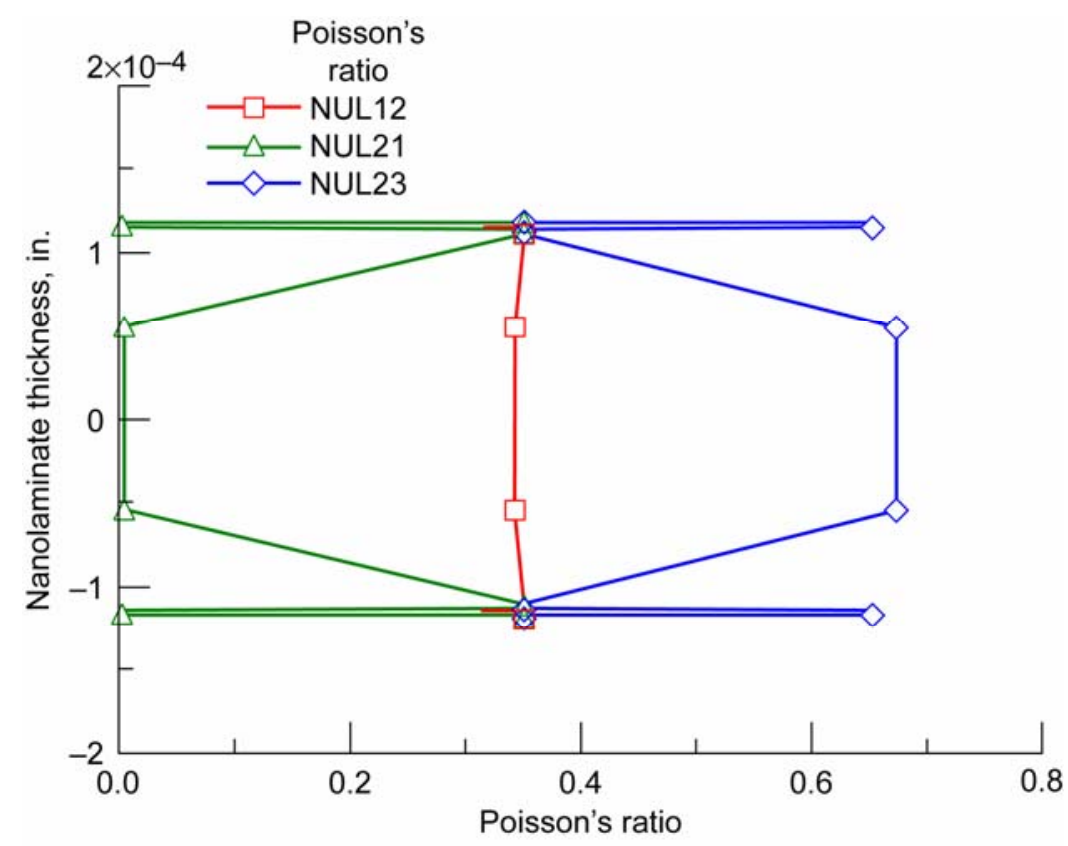

Figure 10.-Nanolaminate Poisson's ratios. Numbers on symbols refer to material axes shown in figure $1(\mathrm{a})(1 \mathrm{in} .=2.54 \mathrm{~cm})$.

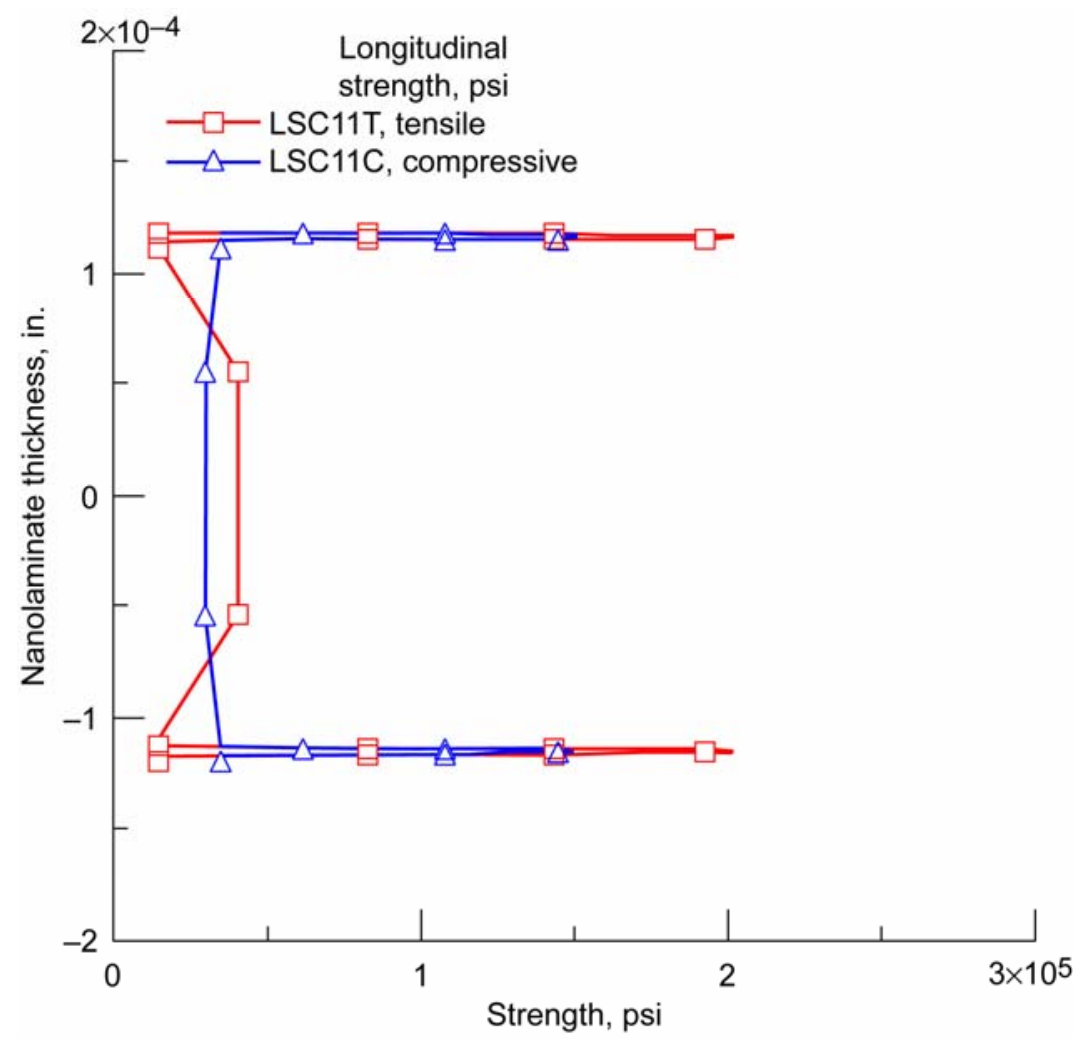

Figure 11.-Nanolaminate longitudinal tensile and compressive strengths. Numbers on symbols refer to material axes shown in figure 1 (a) $(1 \mathrm{psi}=6.9 \mathrm{~Pa}, 1 \mathrm{in} .=2.54 \mathrm{~cm})$. 


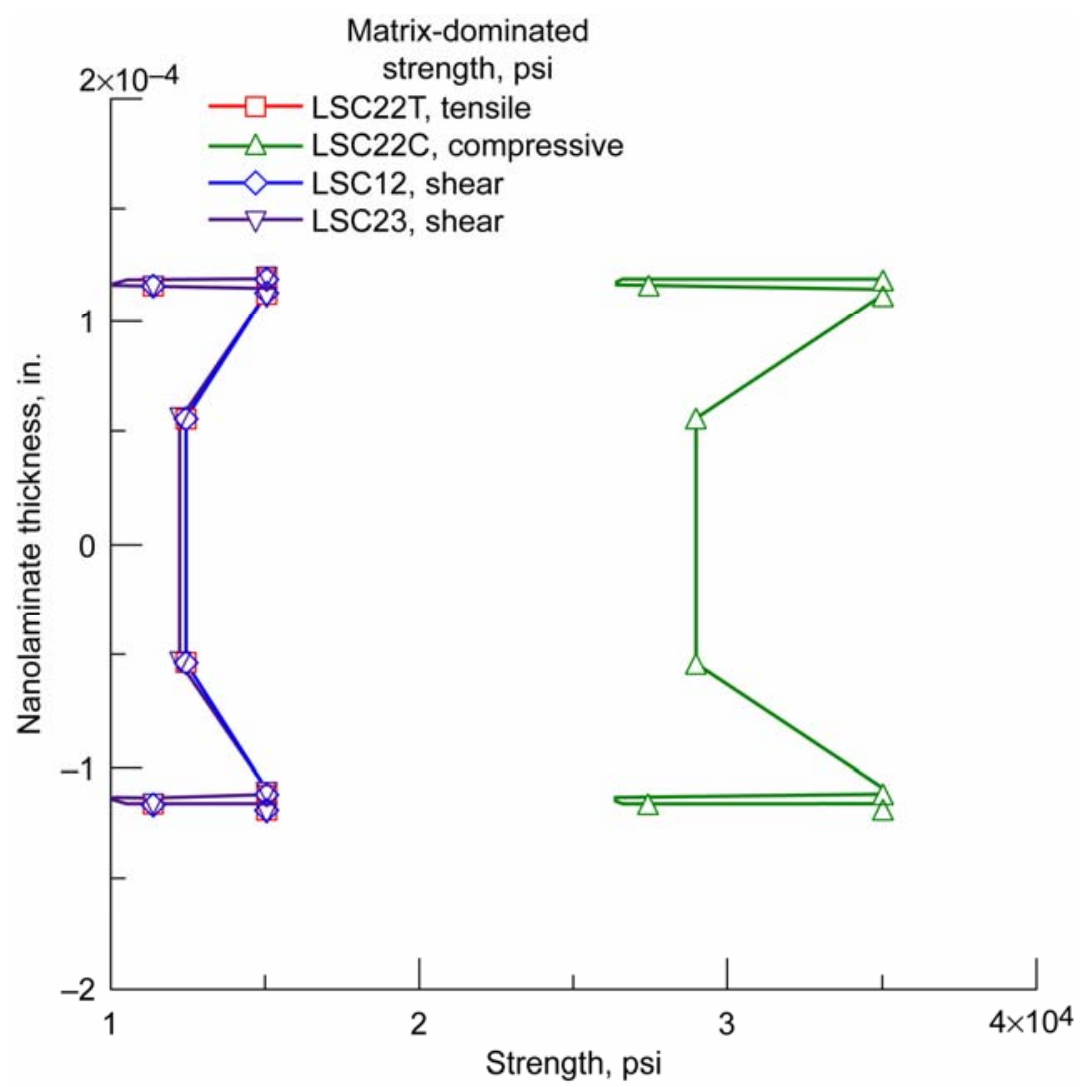

Figure 12.-Nanolaminate matrix-dominated strengths. Numbers on symbols refer to material axes shown in figure $1(\mathrm{a})(1 \mathrm{psi}=6.9 \mathrm{~Pa}, 1 \mathrm{in} .=2.54 \mathrm{~cm})$. 


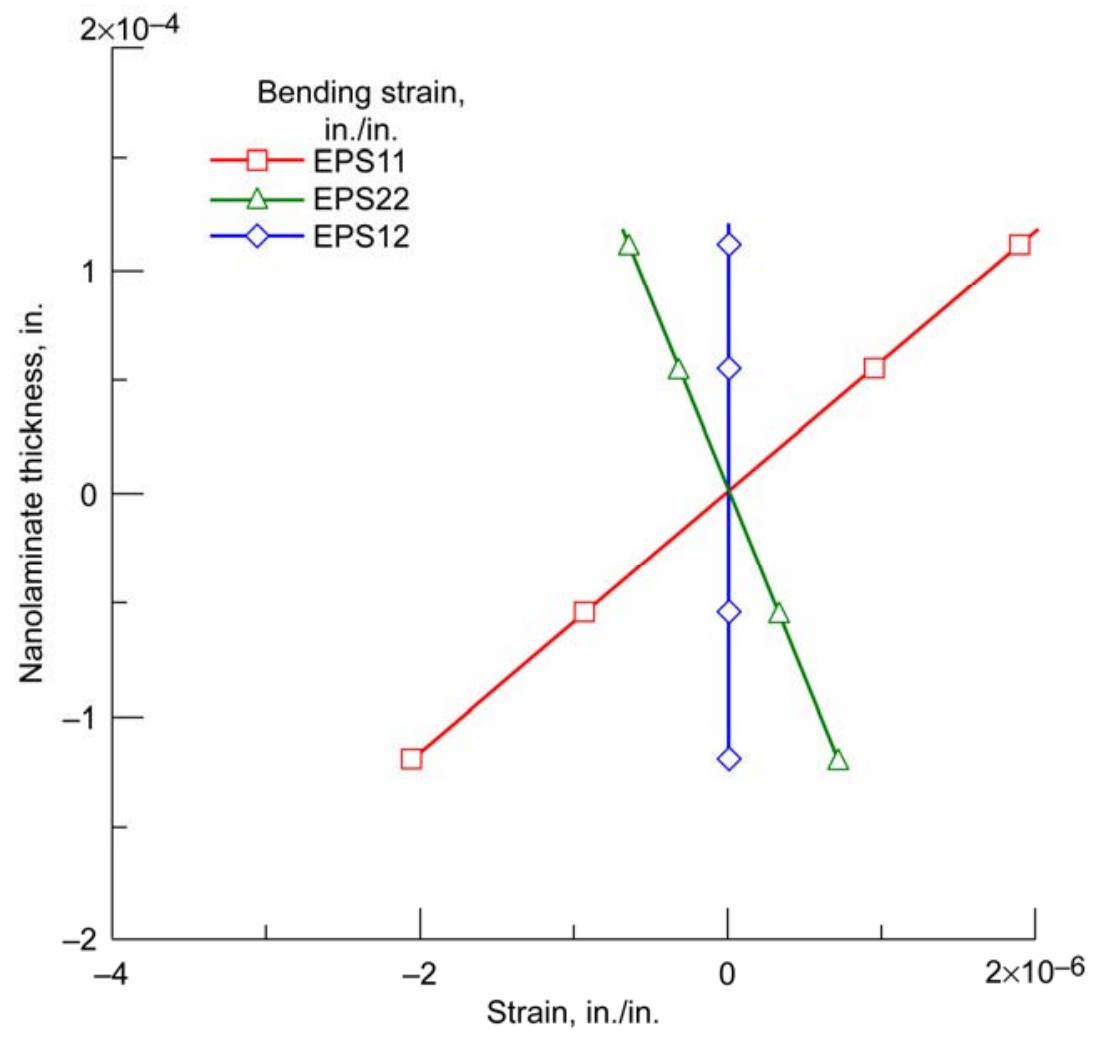

Figure 13.-Nanolaminate bending strains. Numbers on symbols refer to material axes shown in figure $1(\mathrm{a})(1 \mathrm{in} .=2.54 \mathrm{~cm})$.

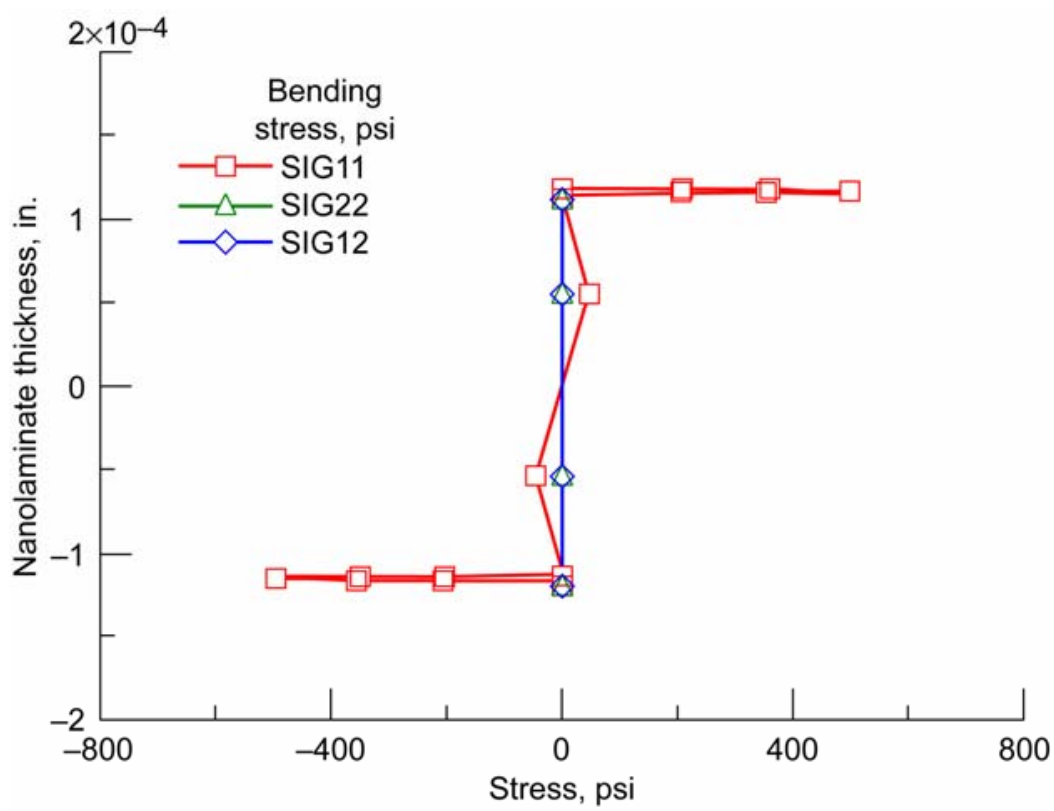

Figure 14.-Nanolaminate bending stresses. Numbers on symbols refer to material axes shown in figure $1(\mathrm{a})(1 \mathrm{psi}=6.9 \mathrm{~Pa}, 1 \mathrm{in} .=2.54 \mathrm{~cm})$. 


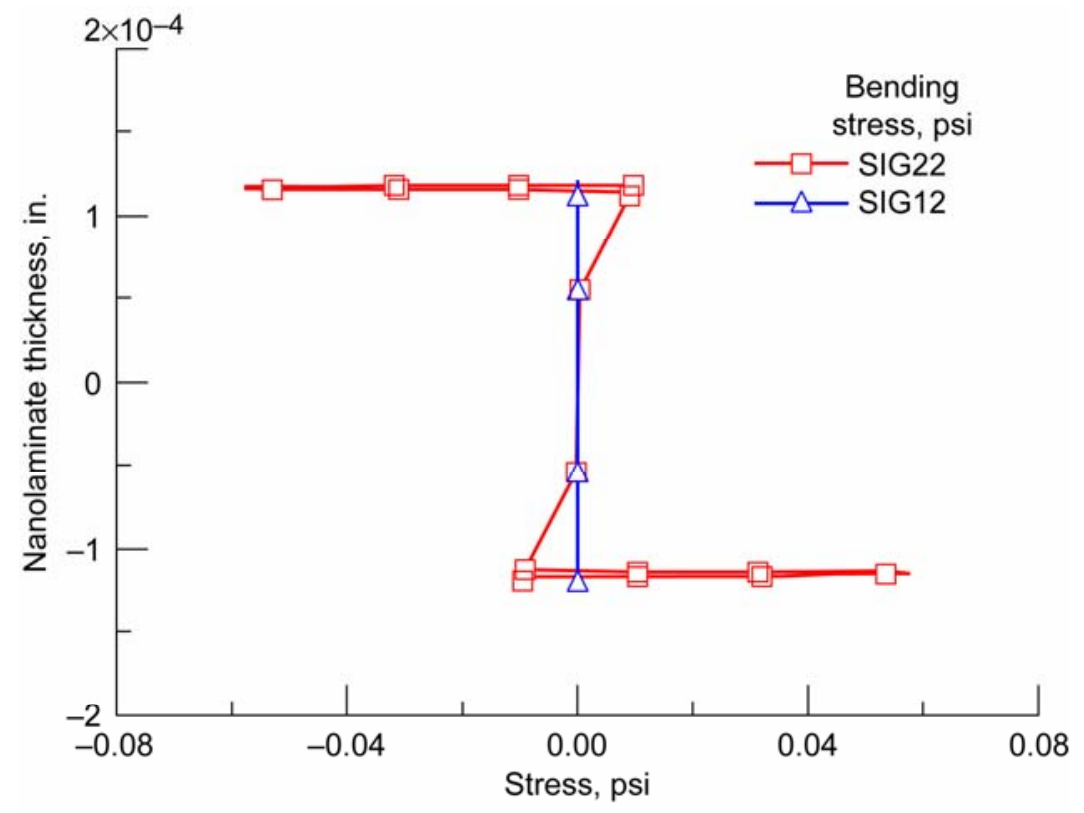

Figure 15.-Nanolaminate matrix-dominated bending stresses, detail from figure 14. Numbers on symbols refer to material axes shown in figure 1(a) (1 psi = 6.9 Pa, 1 in. $=2.54 \mathrm{~cm})$.

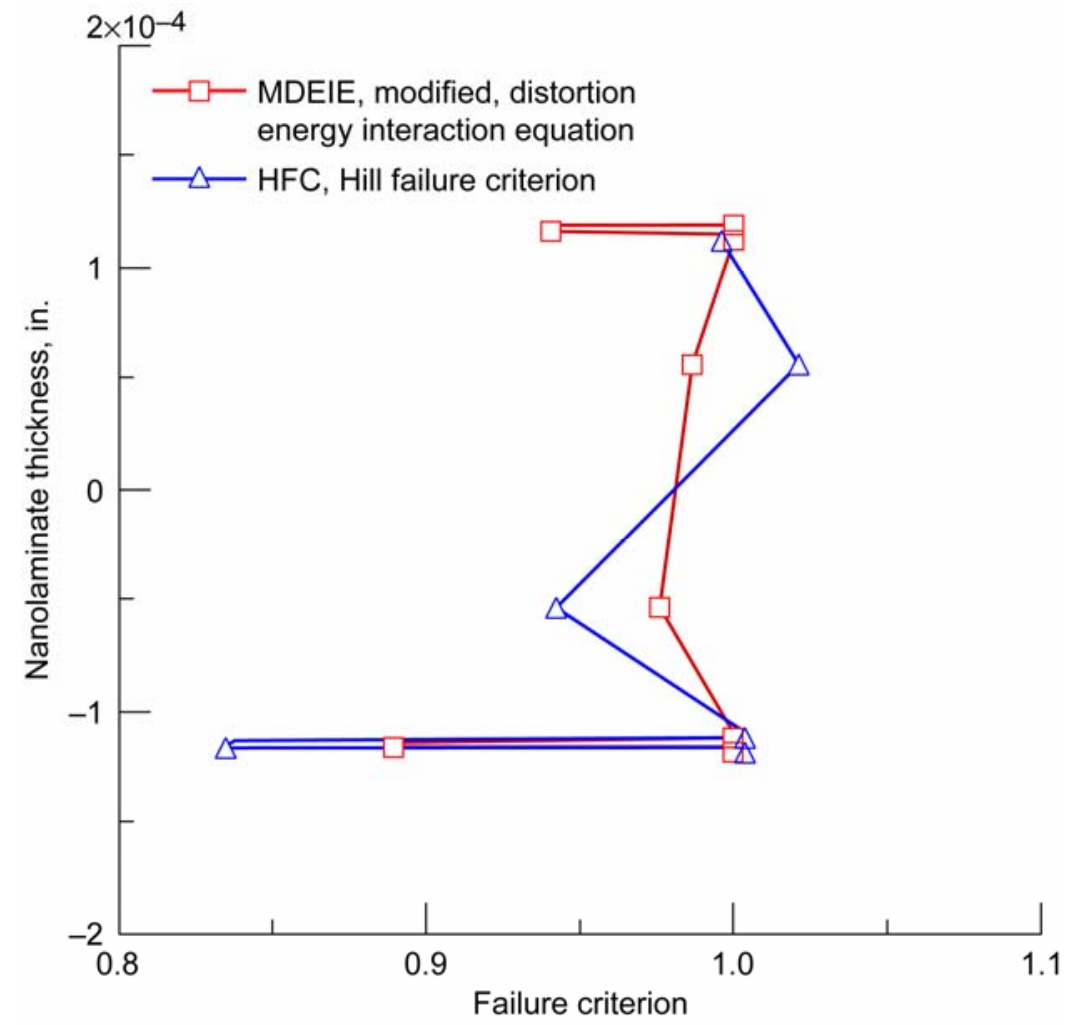

Figure 16.-Nanolaminate combined stress failure criteria. 


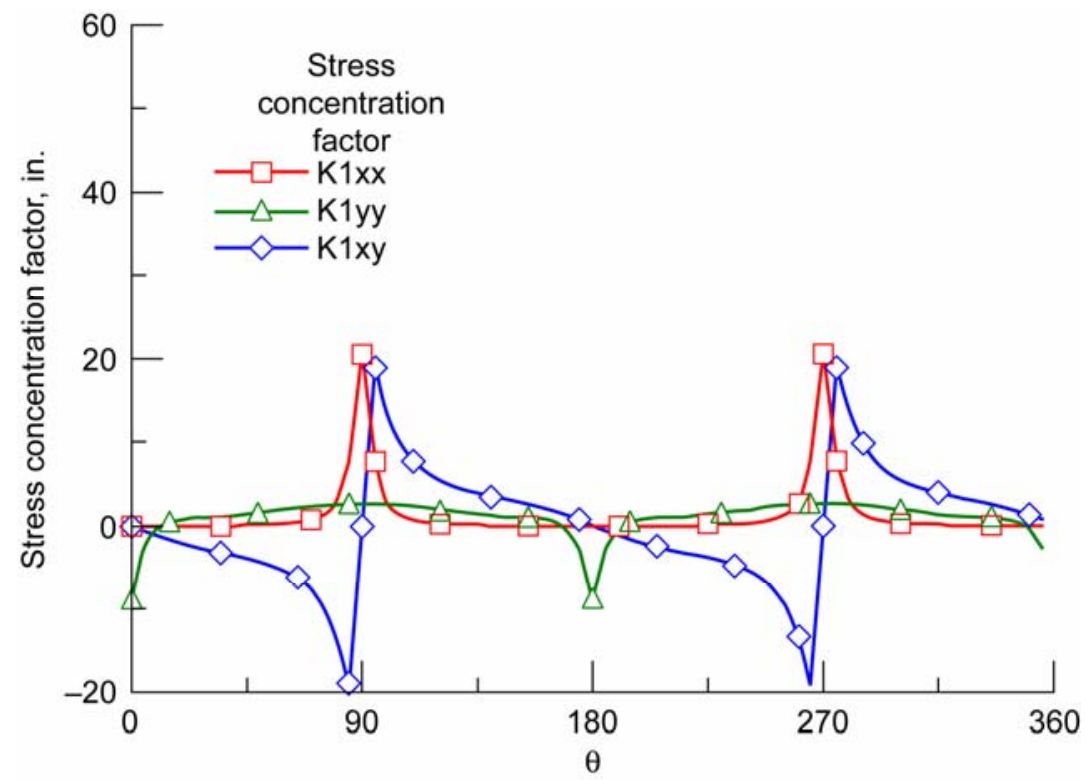

Figure 17.-Nanolaminate stress concentration factors. Coordinate axes are shown in figure 22 .

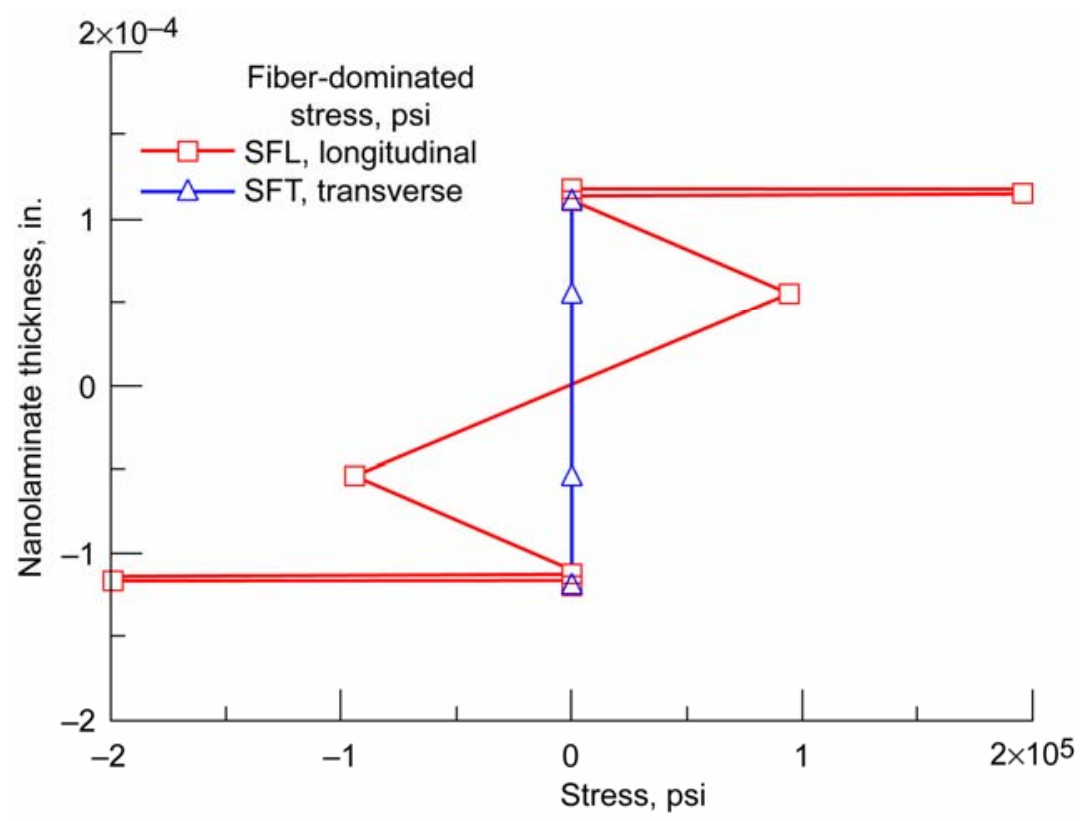

Figure 18.-Nanoelement fiber-dominated longitudinal and transverse flexural stresses $(1 \mathrm{psi}=6.9 \mathrm{~Pa}, 1$ in. $=2.54 \mathrm{~cm})$. 


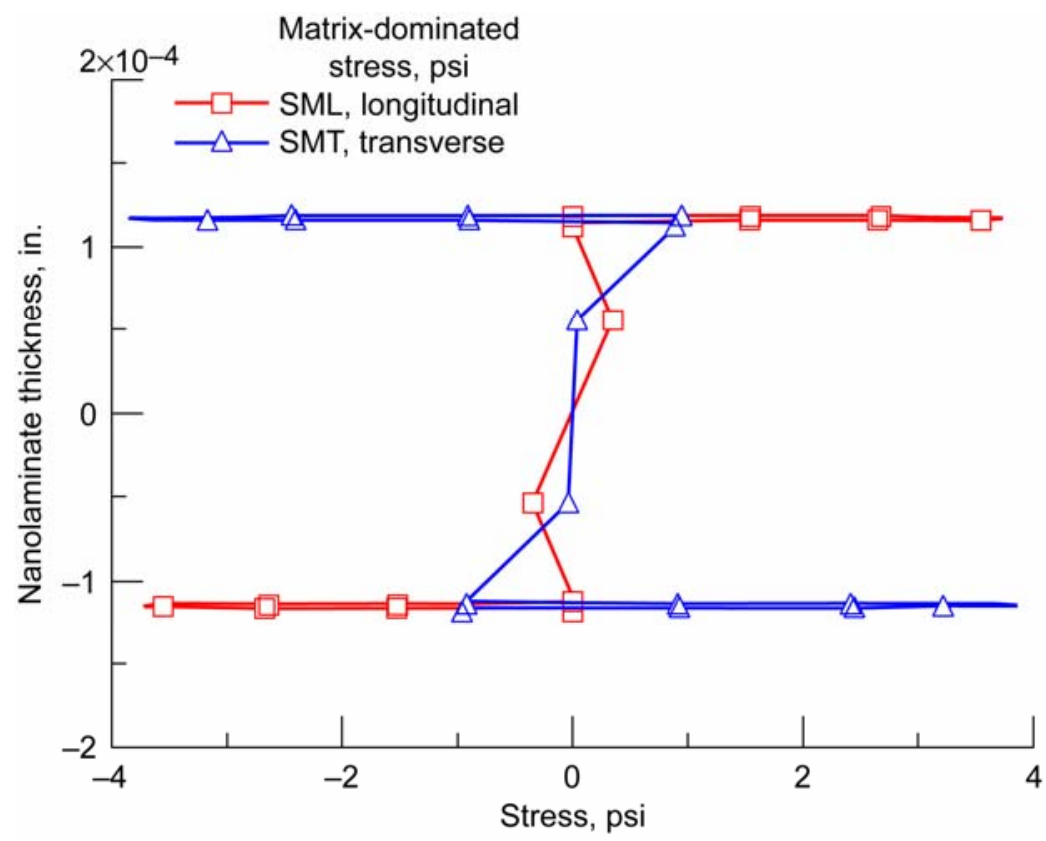

Figure 19.-Nanoelement matrix-dominated longitudinal and transverse stresses (all-matrix region) ( $1 \mathrm{psi}=6.9 \mathrm{~Pa}, 1 \mathrm{in} .=2.54 \mathrm{~cm}$ ).

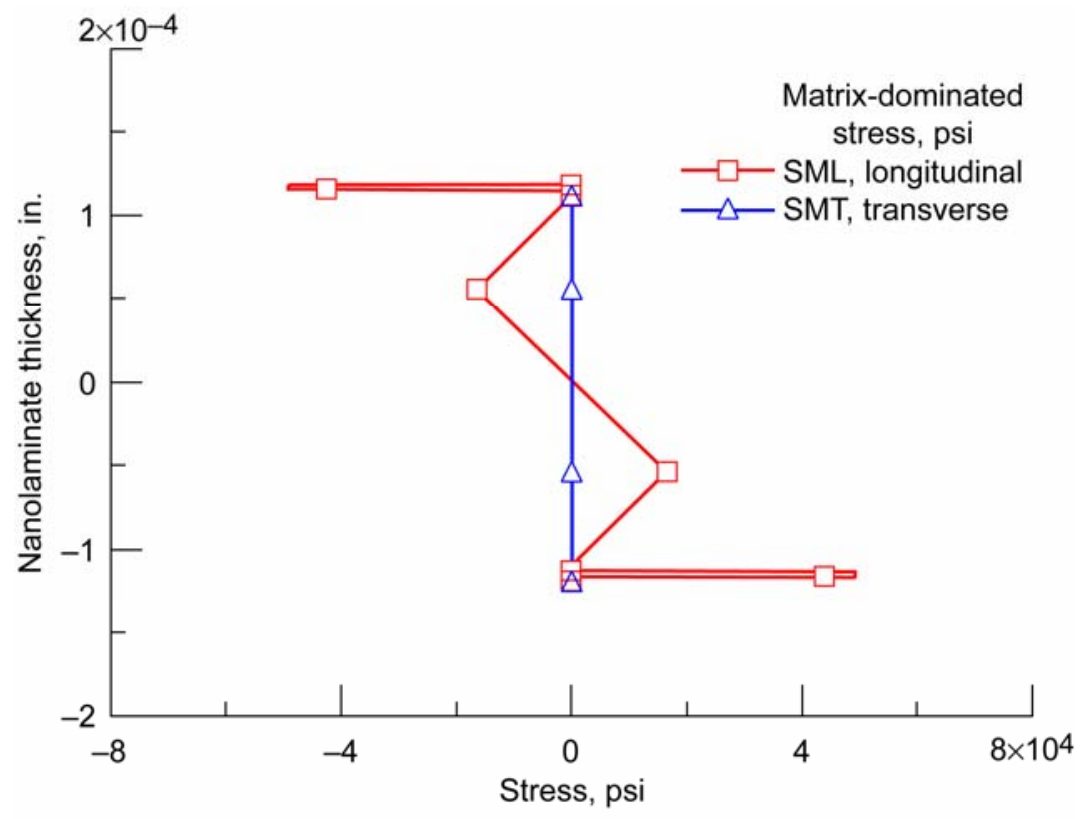

Figure 20.-Nanoelement matrix-dominated longitudinal and transverse stresses (matrix between fibers). ( $1 \mathrm{psi}=6.9 \mathrm{~Pa}, 1 \mathrm{in} .=2.54 \mathrm{~cm}$ ). 


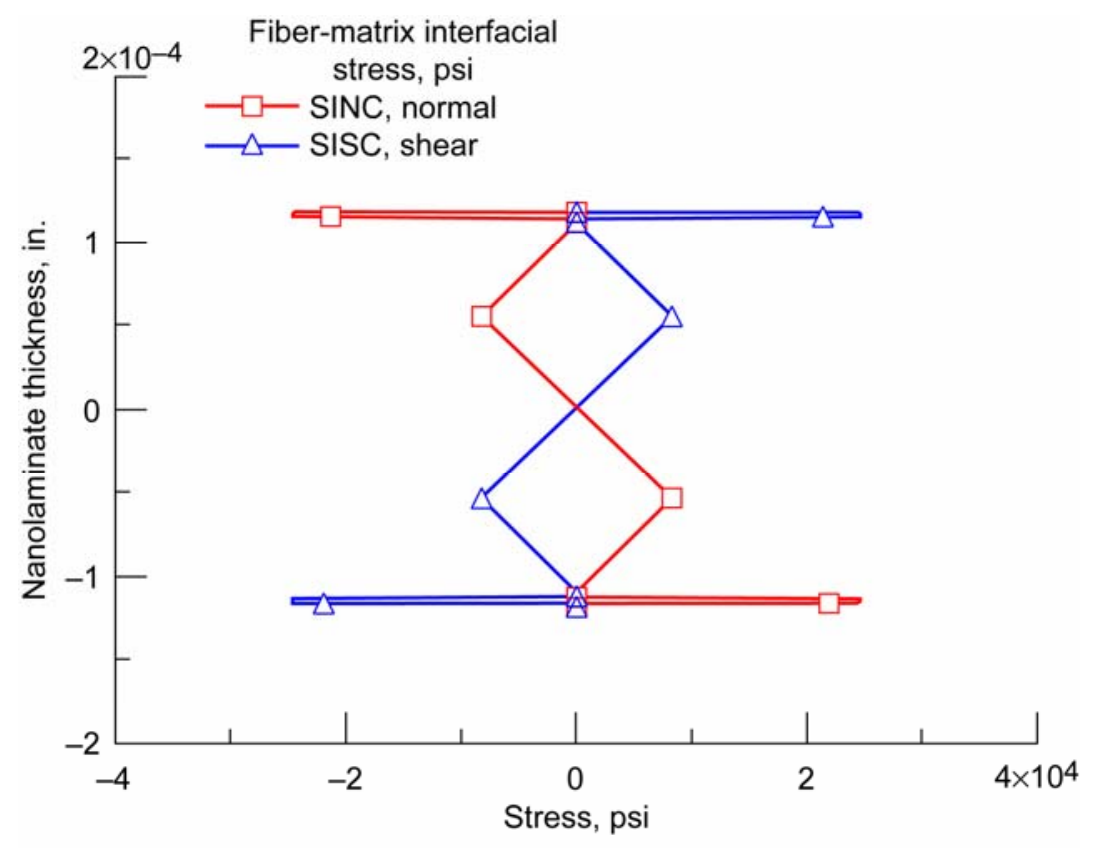

Figure 21.-Nanoelement fiber-matrix interfacial normal and shearing stresses at $45^{\circ}$ from the fiber axis $(1 \mathrm{psi}=6.9 \mathrm{~Pa}, 1 \mathrm{in} .=2.54 \mathrm{~cm})$.
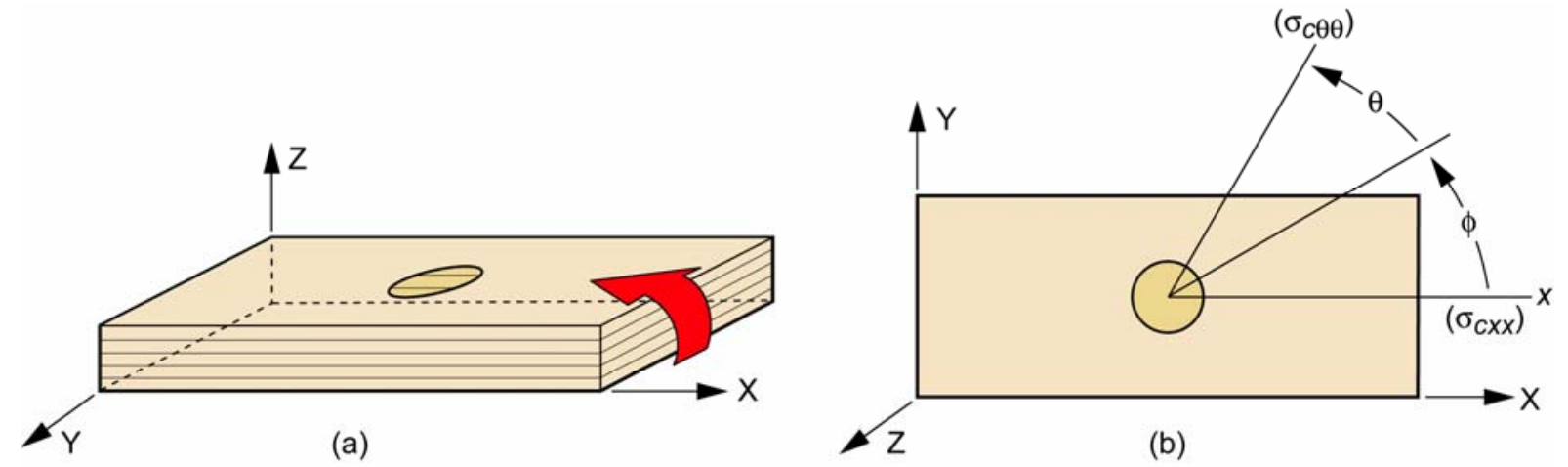

Figure 22.-Definitions of axes for evaluation of nanocomposite stress concentration. (a) Structural axes (X, Y, Z). (b) Coordinate axes for stress concentration. 


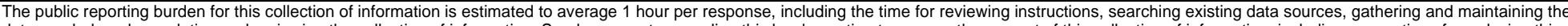

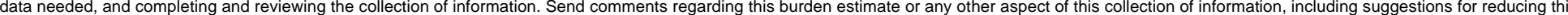

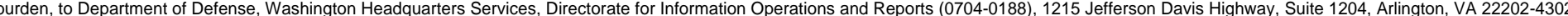

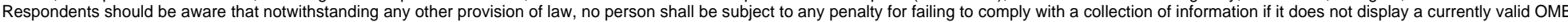
control number.

PLEASE DO NOT RETURN YOUR FORM TO THE ABOVE ADDRESS.
1. REPORT DATE (DD-MM-YYYY)
2. REPORT TYPE

\section{DATES COVERED (From - To)}

01-01-2008

\section{TITLE AND SUBTITLE}

Technical Memorandum

Stress Analysis and Fracture in Nanolaminate Composites

\section{AUTHOR(S)}

Chamis, Christos, C.

\section{5a. CONTRACT NUMBER}

5b. GRANT NUMBER

5c. PROGRAM ELEMENT NUMBER

5d. PROJECT NUMBER

5e. TASK NUMBER

5f. WORK UNIT NUMBER

WBS 561.02.08.03.15.03

\section{PERFORMING ORGANIZATION NAME(S) AND ADDRESS(ES)}

National Aeronautics and Space Administration

John H. Glenn Research Center at Lewis Field

Cleveland, Ohio 44135-3191

9. SPONSORING/MONITORING AGENCY NAME(S) AND ADDRESS(ES)

National Aeronautics and Space Administration

Washington, DC 20546-0001

\section{DISTRIBUTION/AVAILABILITY STATEMENT}

Unclassified-Unlimited

Subject Categories: 24 and 39

Available electronically at http://gltrs.grc.nasa.gov

This publication is available from the NASA Center for AeroSpace Information, 301-621-0390

\section{SUPPLEMENTARY NOTES}

\section{ABSTRACT}

A stress analysis is performed on a nanolaminate subjected to bending. A composite mechanics computer code that is based on constituent properties and nanoelement formulation is used to evaluate the nanolaminate stresses. The results indicate that the computer code is sufficient for the analysis. The results also show that when a stress concentration is present, the nanolaminate stresses exceed their corresponding matrix-dominated strengths and the nanofiber fracture strength.

\section{SUBJECT TERMS}

Nanofiber properties; Nanoelements; Nanostresses and strains; Cantilever bending

\section{SECURITY CLASSIFICATION OF:}

a. REPORT

$\mathrm{U}$

\section{LIMITATION OF} ABSTRACT

UU
18. NUMBER OF PAGES

24 19a. NAME OF RESPONSIBLE PERSON STI Help Desk (email:help@sti.nasa.gov) 19b. TELEPHONE NUMBER (include area code) 301-621-0390
8. PERFORMING ORGANIZATION

E-15841

DPONSORING/MONITORS

NASA

11. SPONSORING/MONITORING REPORT NUMBER

NASA/TM-2008-214928 

